\title{
XI
}

\section{DUALIDADE EDUCACIONAL, INSTITUTOS FEDERAIS E TERRITÓRIO: UM DEBATE NECESSÁRIO*}

\author{
Larissa de Moura Paquiella
}

\section{INTRODUÇÃO}

As reflexões apresentadas neste capítulo partem das pesquisas realizadas no Grupo de Estudos e Pesquisas em Educação e Serviço Social (GEPESS) e no Trabalho de Conclusão de Curso intitulado "Novas faces da Dualidade Educacional Brasileira: Territorialidade e os Institutos Federais", defendido na Escola de Serviço Social da Universidade Federal Fluminense, em 2019. Com o objetivo de analisar como a política de educação estabelece interface com o espaço urbano, abordaremos a política de expansão e interiorização da Rede de Ensino Profissional, que culminou nos Institutos Federais de Educação, Ciência e Tecnologia, examinado as particularidades da oferta de cursos no IFRJ São Gonçalo, no período 2008/2016.

Fundamentados no método materialista histórico-dialético, analisaremos a totalidade da estrutura social, as particularidades do capitalismo dependente e as singularidades constitutivas da política de educação básica e da configuração urbana, uma vez que o capitalismo não é somente uma realidade econômica, mas também uma realidade política, ideológica e social, como afirmava o saudoso intelectual militante Florestan Fernandes.

O estudo dos elementos estruturantes do modo de produção capitalista demonstra como a realidade concreta é marcada por intensa desigualdade econômica e social, pauperismo, exploração, desumanização e pelo fetichismo da mercadoria conduzindo uma naturalização dessa ordem societária. É a partir desta análise que consideramos fundamental entender a função social da educação escolar em um país capitalista dependente, como o Brasil.

As contradições constitutivas deste modo de produção e reprodução da vida se expressam no espaço escolar, o que afeta diretamente o acesso, a permanência e êxito dos estudantes na política educacional. Assim, apesar de a educação ser um direito social, previsto na Constituição Federal de 1988 e no Estatu-

*DOI - 10.29388/978-65-86678-36-9-0-f.211-228 
to da Criança e do Adolescente de 1990, este é violado sistematicamente, diante da lógica desigual e combinada que se estabelece na sociabilidade capitalista dependente, configurando a dualidade educacional, isto é, uma educação para os filhos da burguesia diferenciada da educação ofertada para os filhos dos trabalhadores.

Consideramos o espaço urbano um elemento relevante de ser apreendido, visto que a dualidade educacional, constitutiva do capitalismo dependente, tem direta relação com a apropriação desigual do território. Dessa maneira, faremos considerações sobre a cidade de São Gonçalo, para caracterizarmos como este espaço se constitui de modo a garantir os interesses capitalistas.

Ainda que diante de uma estrutura social violenta, de ataques e desmontes aos direitos sociais e políticos, há resistência, há tensionamentos e lutas operadas pela classe trabalhadora e seus filhos para defender e construir uma sociabilidade mais justa, igualitária e livre, o que envolve esforços para garantir uma educação emancipadora, de qualidade, pública, gratuita e socialmente referenciada na classe trabalhadora.

Assim, este capítulo está organizado da seguinte maneira: I - Formação social brasileira, território e educação escolar no capitalismo dependente; II - As configurações territoriais e as violações sistemáticas de direitos; III - A interiorização dos IFs e a resistência dos secundaristas.

Nessa construção, o pensamento sociológico e educacional de Florestan Fernandes é um marco elucidativo, diante da lucidez do autor para apreender a realidade brasileira e suas complexidades estruturais e conjunturais. Portanto, estabeleceremos interlocuções com o sociólogo para fundamentarmos as reflexões trazidas, caracterizando a relação que se estabelece entre a formação social brasileira, o território e a educação.

\section{FORMAÇÃO SOCIAL BRASILEIRA, TERRITÓRIO E EDUCAÇÃO ESCOLAR NO CAPITALISMO DEPENDENTE}

É importante entendermos que o modo de produção capitalista é construído socialmente, não é natural à organização da vida humana, apesar das constantes e diversas tentativas de naturalização dessa ordem societária. Dessa forma, ressalta-se que o capitalismo é o único modo de produção que se universaliza no mundo e isso se dá de forma desigual e combinada entre os povos e os territórios. 
A partir desta perspectiva, resgatamos as produções de K. Marx, F. Engels, V. Lenin, L. Trotsky e A. Gramsci, para compreendermos o papel do Estado na ordem burguesa, garantindo a produção e a reprodução da sociedade de classes e, dessa maneira, entendermos os mecanismos de coerção e consenso conduzidos pela burguesia, diante dos tensionamentos e disputas sociais que passam também pela configuração das políticas sociais em sua relação direta com a educação e o território. Esses pontos cumprem efeitos diretos e importantes para nossa apreensão: a inserção dependente do Brasil na economia mundial; a composição dicotômica dos territórios e os acessos diferenciados e desiguais às políticas sociais e equipamentos públicos ou privados, do território e da educação.

Nesse sentido, para uma compreensão mais aprofundada do que é o Brasil contemporâneo, sua inserção na economia mundial, que é caracterizada por Fernandes (1976, p. 222) como "periférica e heteronômica", e o que as políticas educacional e territorial representam, devemos retomar os estudos elaborados pelo autor sobre a formação social brasileira, com sua origem escravocrata e colonizadora; abordando a origem e consolidação das classes burguesa e trabalhadora e considerando os processos de mercantilização da força de trabalho que ocorreram no Brasil, conforme examinado nos capítulos anteriores.

Dessa maneira, Florestan Fernandes analisa ao longo de sua obra os diferentes padrões de dominação externa, a saber: colonialismo, neocolonialismo, imperialismo restrito/ capitalismo dependente e imperialismo total. Estes vão moldando a estrutura do país, com novidades e continuidades, com o objetivo de garantir maior lucratividade para o capital, por meio da expropriação da força de trabalho, mantendo e ampliando os privilégios da burguesia em sua dupla face: local e internacional. Conforme caracterizado pelo autor, a organização do poder é "[...] aristocrática, oligárquica e plutocrática, engajados na riqueza, prestígio social e poder, institucionalizando a exclusão permanente do povo e o sacrifício consciente de um estilo democrático de vida" (FERNANDES, 1975a, p. 12).

Diante dessa realidade, em que a exclusão permanente dos trabalhadores é elemento constitutivo do capitalismo dependente, ressaltamos que a relação entre a burguesia local e o imperialismo não é apenas uma estratégia econômica, pelo contrário, é considerado um “[...] componente dinâmico de uma tradição colonial de subserviência consentida, elementos de uma cegueira nacional estimulada e controlada por fora". (ibidem, p. 12). 
Fernandes (1976) salienta as particularidades da burguesia brasileira, que, por aqui, não operou uma revolução burguesa "clássica", quando utilizamos como parâmetro histórico os países centrais. Na realidade brasileira, vivemos uma passagem do Império para a República, sem o colapso do poder oligárquico. O que ocorre é uma transição que gera uma recomposição de poderes, coexistindo aspectos arcaicos e modernos, estabelecendo um pacto entre a burguesia brasileira e as oligarquias coloniais e mantendo pilares colonizadores, agrários-latifundiários e escravocratas revitalizados no desenvolvimento do capitalismo.

Por sua vez, a burguesia brasileira assume o seu caráter antidemocrático e antinacionalista, em prol de exercer seus domínios, poderes e prestígios, bem como viabilizar a reprodução da ordem social capitalista. Fernandes (1995) analisa o padrão compósito de hegemonia burguesa, evidenciando o quanto as frações burguesas se unificam, acoplando também a burguesia internacional, para garantir seu projeto de sociabilidade, evidenciando que, ainda que haja disputas e diferenças entre elas, o pacto de dominação estabelecido entre as frações burguesas deverá ser preservado.

A dependência consentida e conduzida pela burguesia brasileira manterá o subdesenvolvimento como estratégia para garantir a lucratividade e a dominação de classe. A isso, está vinculado o padrão dual de expropriação do excedente econômico, que consiste em uma intensa exploração da classe trabalhadora, suprindo financeiramente os países imperialistas por meio da extração da mais-valia dos trabalhadores brasileiros e com isso, agudizando ainda mais as desigualdades econômicas e sociais. A burguesia ganhava, assim, as condições mais vantajosas possíveis: 1) para estabelecer uma associação mais íntima com o capitalismo financeiro internacional; 2) para reprimir, pela violência ou pela intimidação, qualquer ameaça operária ou popular de subversão da ordem (mesmo com uma "revolução democrático-burguesa"); 3) para transformar o Estado em instrumento exclusivo do poder burguês, tanto no plano econômico quanto nos planos social e político. (FERNANDES, 1975a, p.217, apud LIMA, 2005, p. 185).

Fernandes (2013) apreende de forma conjunta a dependência econômica com a heteronomia cultural, entendendo que o capitalismo, conforme foi ressaltado anteriormente, não é apenas uma realidade econômica, mas uma forma de ser e estar no mundo. Neste sentido, ressalta a tendência de buscar na Europa e nos Estados Unidos os pilares de formação, “[...] pontos de referência permanente", formando um "[...] estado de dependência fundamental" (FER- 
NANDES, 2013, p. 220). Diante desse cenário, o eurocentrismo se manifesta como uma das consequências, reforçando uma estrutura de normatividade pautada na perspectiva ocidental: capitalista, liberal, branca, moderna, civilizada nas ordens ocidentais, heteronormativa, fazendo com que a violência, o racismo estrutural e o epistemicídio ${ }^{1}$ se configurem como elementos estruturantes da inserção capitalista dependente do Brasil na economia mundial.

Nos limites deste texto, podemos perceber como as elaborações teóricas e políticas de Florestan Fernandes nos desvendam a natureza violenta e conservadora da burguesia brasileira, que não conduz sequer as pautas inerentes ao próprio capitalismo, como a reforma agrária, urbana, educacional, democrática, entre outras.

Dessa forma, espaços educacionais e universitários já nascem, no Brasil, numa "[...] composição de resíduos educacionais ou institucionais arcaicos com interesses estamentais ou de classes.” (FERNANDES, 1975b, p. 113). Tal processo interfere diretamente na função social da educação, reforçando fatores como alienação, farsa intelectual sistemática e a heteronomia cultural. Ademais, estabelece uma dualidade educacional que é estruturante do capitalismo: uma escola para os filhos da classe dominante e outra para os filhos da classe trabalhadora. Esse processo é compreendido por Florestan Fernandes (1975) como "senilização institucional precoce", caracterizando a composição de elementos arcaicos e modernos num mesmo espaço e isso, dentro da ótica burguesa, não é uma contradição e sim, elemento indispensável para demarcar os limites possíveis do sistema.

O pensamento educacional florestaniano é bem incisivo ao denominar o "colonialismo educacional" como projeto de uma educação dependente, conforme analisado nos capítulos anteriores. É importante frisar que há disputas em curso, historicamente, sobre os projetos para educação, sobre os modelos de escola e universidade.

Não devemos esquecer, portanto, alguns elementos constitutivos da ordem burguesa: a) a maioria dos indivíduos também se encontra alijada, em maior ou menor grau, das formas de poder: econômico, político, cultural, social e educacional; b) o Estado não representa os interesses de todos, mas ergue-se sobre as desigualdades de classes existentes e, como essa superestrutura, tam-

\footnotetext{
${ }^{1} \mathrm{O}$ epistemicídio é um conceito reivindicado na literatura crítica decolonial que se refere a todo o processo de apagamento, aniquilamento, subalternização dos conhecimentos, das culturas e tradições, de todas as formas de viver que não são hegemônicas. Ressalto a pesquisadora Sueli Carneiro (2005) que em sua construção teórica, amplia a análise sobre o epistemicídio e as consequências individual e coletiva sobre essa desapropriação associada a uma imposição cultural hegemônica.
} 
bém é contraditória, do Estado não decorre apenas o papel de conservação de tais relações, muito embora este seja seu fundamento; c) a esta sociedade corresponde uma determinada forma de democracia, não uma democracia em geral, pois, formas particulares de desenvolvimento capitalista nas distintas formações sociais limitam as formas de democracia possíveis em cada contexto histórico. (MINTO, 2014).

$\mathrm{Na}$ tentativa de associar esses conceitos fundamentais, para entendermos a formação social brasileira e seus pilares compondo o capitalismo dependente, avançamos no debate para perceber como estes elementos estruturais se manifestam em tempos neoliberais. É fundamental considerar as alterações advindas da reestruturação produtiva, a partir das décadas de 1980 e 1990, bem como compreender o papel político desempenhado pelos organismos internacionais do capital, que se articulam como sujeitos políticos coletivos do capital intervindo diretamente nas reformas estruturais dos países latino americanos; na refuncionalização do Estado, por meio de liberalização, privatização e desregulamentação da economia, além de difundirem e legitimarem os valores do neoliberalismo, como o individualismo e a meritocracia.

A agenda pautada pela burguesia internacional foi consentida e conduzida pela burguesia nativa e a educação profissionalizante é um dos projetos apresentados. Dessa forma, os Institutos Federais são pensados, estabelecendo críticas ao modelo universitário europeu, visando o aligeiramento da formação e a capacitação profissional, assim, as alternativas postas como viáveis para efetivar esse projeto são expressas na profissionalização não universitária, de curta duração (de no máximo dois anos) e fortalecendo o apelo ao ensino a distância. Para além disso, Gleyce Lima (2017) faz apontamentos sobre o modelo de gestão dessa política educacional que viabiliza uma inserção gradual de instituições privadas na esfera pública, instituindo parcerias público privadas e uma lógica de promoção de 'serviços educacionais' e os indicadores de eficiência do 'gasto público’ são avaliados diante de uma ótica mercadológica.

Dessa maneira, no intuito de promover um modelo de desenvolvimento focado na formação de superávit primário, visando o pagamento da dívida externa e o corte da alocação de valores públicos para educação pública, o governo federal (2003/2016) identificou que o Instituto Federal cumpriria uma demanda por capilaridade nacional, isto é, um instituto que “[...] ocupe espaços geográficos capazes de atender às demandas requisitadas pelo mercado de trabalho e com a disposição de se fazer presente em todas regiões economicamente importantes". (LIMA, 2017, p. 97). 
O padrão dependente de educação constitutivo do padrão dependente de desenvolvimento (examinado nos capítulos anteriores) fundamentará, portanto, a dualidade educacional marcando o processo de criação e organização dos institutos federais, situados em determinados territórios da cidade caracterizados pela profunda desigualdade econômica e social. Assim, a fim de entender como se dá essa capilaridade territorial, traçaremos reflexões sobre a constituição do espaço urbano na sociabilidade capitalista dependente, com destaque ao Estado do Rio de Janeiro e a cidade metropolitana de São Gonçalo para percebermos como o território e educação se intercruzam.

\section{AS CONFIGURAÇÕES TERRITORIAIS E AS VIOLAÇÕES SISTE- MÁTICAS DE DIREITOS}

A cidade que conhecemos atualmente foi criada a partir de diversas mediações políticas, sociais, econômicas e históricas, conforme analisa Lefebvre (2001) em seus estudos sobre como a cidade capitalista foi se moldando ao longo do tempo.

Em países centrais, a vida rural se tornou cada vez menor em proporção à vida urbana, e isso tem direta influência com o cercamento dos campos e a industrialização, como é analisado na obra O Capital de Karl Marx. Portanto, destrinchar esse modelo urbano como parte da formação social brasileira é um dos desafios desta pesquisa. Estes elementos devem ser considerados, visto que as expressões da questão social se manifestam nessa arena urbana e, por vezes, são postas como caos e desordem urbana, mas essa compreensão, na realidade, mascara as relações e forças sociais que a compõem, gerando impactos, violações e violências que se expressam tanto no espaço escolar, quanto na reprodução da vida social em si.

Dessa forma, Abreu (2008, p. 11) afirma que “[...] o alto nível de estratificação social do espaço metropolitano no Rio de Janeiro, na atualidade, é apenas uma expressão mais acabada de um processo de segregação das classes populares que vem se desenvolvendo no Rio de Janeiro há muito tempo". Nesse sentido, historicamente, foram diversas configurações legais e políticas que deram respaldo para formular uma estrutura urbana elitista, desigual e profundamente racista, tendo em vista, por exemplo, a Lei de Terras de 1850 e o Código de Posturas Municipal do Rio de Janeiro de 1898.

O Rio de Janeiro foi capital do Brasil entre os anos de 1763 a 1960 e isso gerou um movimento de se tornar referência de cidade para as demais cida- 
des do Brasil. Para tal, ocorreram ações de perseguição e culpabilização da população pobre, sobretudo pelos surtos de febre amarela, tendo o Estado como promotor de políticas higienistas, racistas e classistas, em prol de viabilizar espaços de criação, concentração e acumulação do capital e transfigurando a cidade modelo.

A Reforma Pereira Passos, em 1903, foi um marco de grande transformação do espaço carioca. Três aspectos são ressaltados por Abreu (2008) sobre essa reforma e que revelam suas novidades: 1) "[...] movimentos de organização social determinam as funções da cidade" (idem, p. 65) e para alcançar isso, há uma movimentação de eliminar tudo aquilo que não é visto como útil para ordem capitalista. 2) "[...] é o primeiro exemplo de intervenção estatal maciça sobre o urbano, reorganizado agora sobre novas bases econômicas e ideológicas, que não mais condiziam com a presença de pobres na área mais valorizada da cidade" (idem, p. 65). 3) Sobre o surgimento de novas contradições, relacionado ao crescimento populacional nas favelas, que se fez como "[...] a única alternativa que restou a uma população pobre, que precisava residir próximo ao local de emprego." (idem, p. 66). Trazer essas pontuações cumpre o papel de desmistificar a dita "Cidade Maravilhosa", visto que está na sua constituição o cerceamento violento e as violações de direitos sociais básicos para classe trabalhadora, como a moradia, o transporte, o saneamento básico, a saúde integral, a educação, o lazer, enfim, viver com dignidade.

É a partir destas análises que apresentamos algumas reflexões sobre o município de São Gonçalo - local onde está localizado o campus do Instituto Federal do Rio de Janeiro que analisamos com maior especificidade neste texto. Compondo a região metropolitana do Rio de Janeiro, São Gonçalo passa por diversas transformações sociais, territoriais, políticas e produtivas. Seu surgimento é datado a partir do século XVI, com presença de povos indígenas, sobretudo, os Tamoios. Ao longo do tempo, colonizadores jesuítas começaram a intervir na região, e, assim, a cidade torna-se destaque em atividades de ordem alimentícia, organizando-se um grande celeiro alimentar e agrícola da região.

Segundo Vianna (2019) e Moraes (2016), nos anos de 1920 a 1940, São Gonçalo passa por um forte processo industrial, gerando mudanças nas políticas públicas de urbanismo, envolvendo calçamento de ruas, implantação do transporte ferroviário, entre outras ações. Já na década de 1950, o perfil do município se modifica e a região passa ser habitada por trabalhadores que vão servir de força de trabalho em outras cidades, como Niterói e Rio de Janeiro. Nesse momento, inicia-se lentamente o processo de desindustrialização, que se agu- 
diza em 1980 e isso consagra um espaço de intensa desigualdade econômica e contradições sociais. Esse processo está relacionado diretamente com os fluxos migratórios duplamente induzidos, de um lado, via expulsão das populações mais pobres residentes no núcleo ou na periferia imediata e, por outro, por meio do deslocamento de trabalhadores que se mudam para a cidade do Rio de Janeiro, em busca de empregos.

A segregação espacial se materializa e segue apresentando diferentes fases até os dias atuais, se acentuando, ainda mais, com o neoliberalismo. Vianna (2019) considera que o processo de urbanização envolve uma modulação de periferização-espoliação-segregação, e isso se dá numa simbiose de novidades e continuidades.

Os dados sobre o município de São Gonçalo demonstram que, em termos populacionais, é o segundo município mais populoso do Estado do Rio de Janeiro e está em $16^{\circ}$ lugar no ranking das cidades do Brasil (IBGE, 2010). Diante dessa configuração, a população está exposta a precarizações, violações e ações violentas operadas por grupos armados, inclusive, através de e/ou com respaldo do próprio Estado, que controlam e dominam os territórios.

Nessa confluência entre arcaico e moderno, estabelece-se uma lógica de "desenvolvimento" para o capital que se dá através de investimentos privados no território, nutrindo os interesses da burguesia local e internacional sobre projetos de cidade e de educação. Temos como exemplo o COMPERJ (Complexo Petroquímico do Rio de Janeiro), situado em Itaboraí (RJ), cidade vizinha de São Gonçalo, como um dos empreendimentos da Petrobras que envolveu uma agenda de articulação dos interesses capitalistas, projetando no território formas de dominação e expropriação da classe trabalhadora.

Foi nesse contexto de criação do COMPERJ que o IFRJ - Campus São Gonçalo se articulou para atender a formação profissional e técnica dos trabalhadores e filhos de trabalhadores. O foco em educação profissionalizante foi compreendido como uma tarefa importante para o projeto de desenvolvimento da região. Uma educação aligeirada, profissionalizante, voltada para o mercado de trabalho - corroborando na compreensão de que há modalidades distintas de educação para determinadas localidades, mantendo a utilidade e a funcionalidade da educação e do território à ordem societária capitalista dependente.

A oferta de uma educação aligeirada para os trabalhadores e filhos de trabalhadores de São Gonçalo constitui a manifestação de uma das faces da dualidade educacional, associadas ao racismo e a eugenia estruturais e operando a estigmatização da juventude preta, pobre e periférica. Este conjunto de análises 
nos indicam várias reflexões: que projeto é esse que está em curso para a juventude com a política de interiorização e expansão dos Institutos Federais? A quem esse projeto atende? Quais os interesses em disputa no projeto de educação ofertada pelo IF São Gonçalo? Como os estudantes do referido IF avaliam a educação que lhes é ofertada e as condições de acesso e permanência no instituto?

\section{A INTERIORIZAÇÃO DOS IFS E A RESISTÊNCIA DOS SECUNDA- RISTAS}

Nesse momento, objetivamos traçar uma breve análise sobre a política de expansão e interiorização da Rede Federal de Educação Profissional Científica e Tecnológica (RFEPCT) que culminou nos Institutos Federais. Assim, é importante destacar os marcos legais que deram respaldo jurídico para essa ação: a revogação do decreto $\mathrm{n}^{\circ}$ 2.208/1997; a implementação do decreto $\mathrm{n}^{\circ}$ 5.154/2004; a promulgação das leis $\mathrm{n}^{\circ} 11.195 / 2005, \mathrm{n}^{\circ} 11.249 / 2005$ e $\mathrm{n}^{\circ}$ 11.892/2008. Para além disso, como apontamos, anteriormente, os organismos internacionais do capital geram, historicamente, materiais que indicam os horizontes que eles enxergam como mais vantajosos, eficazes e eficientes para a educação no Brasil. Lima, G (2017) faz apontamentos sobre o título da sessão de um dos documentos do Banco Mundial "A relação entre desenvolvimento e enfrentamento à pobreza na expansão da Rede EPT" e assim, sustenta:

A expansão da Rede EPT, notadamente a criação dos Institutos Federais, está relacionada às macrodiretrizes do Banco Mundial para os países da periferia do capitalismo mundial. Tal hipótese não incorre no equívoco de considerar que a realização de um projeto dessa magnitude obedece apenas aos ditames externos, sem a vinculação com as elites dirigentes nacionais e/ou locais. (LIMA, 2017, p. 96).

Portanto, a política de expansão da REPCT nasce como uma demanda associada ao projeto de governo de Luiz Inácio Lula da Silva (2003 - 2010), com continuidades no primeiro mandato da Dilma Rousseff (2011-2014) e diante de um projeto de governabilidade pautado na coalizão de classes, conduzido pelo partido, não ocorreram rupturas com o padrão compósito de hegemonia burguesa, com o padrão dual de expropriação de excedente econômico e a heteronomia cultural que alimentaram a dualidade educacional historicamente vigente no Brasil. 
É válido ressaltar o caráter institucional "híbrido e dual" (TEIXEIRA, 2012) que os Institutos Federais comportam. Essa caracterização se dá devido às diferentes modalidades formativas oferecidas na instituição e, por ser uma instituição federal de ensino, é vista socialmente como espaço de "excelência", de prestígio social e status, e isso foi mais aprofundado depois que passou a ser reconhecida como instituição de ensino superior.

Lima, G (2017) analisa o processo denominado de "diferenciação para cima", que se caracteriza na diferenciação que ocorre entre as redes estaduais e municipais de ensino em relação a rede federal. Como consequência dessa condição, há uma interferência direta na estrutura institucional e nas políticas de acesso e permanência estudantil, visto que, por vezes, os próprios gestores compreendem que os estudantes das instituições federais "não precisam" de certas condições para se manter, reforçando uma concepção elitista da instituição e promovendo violação aos direitos básicos dos estudantes da educação básica, como, por exemplo, o direito à alimentação e ao transporte.

É importante perceber que o perfil discente se modifica, sobretudo com a política de interiorização, pois, os Institutos Federais passam a ocupar territórios diversos e marcados por desigualdades econômicas e sociais. A partir da implementação e da efetivação dessas políticas, intensifica-se a demanda por políticas de assistência estudantil que garantam efetivamente a permanência desse estudante na escola (como a política de ações afirmativas instituída pela Lei $n^{\circ} 12.711 / 2012$ ). Contudo, estamos diante de um dilema estrutural relacionado à lógica de "lassidão institucional", apresentada por Lima, G (2017) indicando que dentro da própria estrutura escolar há mecanismos que promovem a exclusão do estudante trabalhador.

Nesse sentido, os fenômenos de não acesso, retenção e evasão representam uma síntese de uma totalidade, envolvendo as análises realizadas anteriormente, bem como aspectos da própria estrutura escolar que passamos a apresentar:

A) O processo seletivo para ingresso dos estudantes na rede federal de ensino via sorteio ou via concurso reforça valores meritocráticos, de competitividade e individualismo, demonstrando o quanto o acesso está longe de ser universalizado.

B) A Política de Assistência Estudantil faz uma interface com as políticas sociais no capitalismo dependente e segue a lógica de focalização e assistencialismo e se agudiza no cenário neoliberal, causando impactos diretos no próprio Programa de Assistência Estudantil do IFRJ/SG. 
C) O passe livre estudantil do Estado do Rio de Janeiro (Lei Estadual $\left.\mathrm{n}^{\circ} 7.830 / 2018\right)$ é restrito a 60 passes mensais, número deficitário para aqueles estudantes que demandam mais de 02 ônibus por dia para realizar o trajeto casa-escola/escola-casa. Além disso, sob essa configuração política, é perceptível a concepção de educação que está em pauta para classe trabalhadora, uma relação de ensino-aprendizagem restrita à institucionalidade, cerceando o direito de ocupar a cidade e os espaços extraescolares, que são fundamentais para a educação mais ampliada.

D) O Projeto Político Pedagógico institucional é constituído por tensionamentos e disputas sobre a condução do modelo educacional no IF. Florestan Fernandes (1995) é firme em apontar que não há neutralidade axiológica e, dessa maneira, dentro do espaço educacional, é preciso coerência e comprometimento ético e político para construir um espaço aliado com os interesses da classe trabalhadora, sem opressões institucionais que reforcem as desigualdades econômicas, sociais, raciais, de gênero e territoriais.

Portanto, partindo dessas reflexões, é importante ressaltar que viemos ao longo dessa construção ressaltando como se expressam essas contradições, evidenciando que não houve uma ruptura com o padrão dependente de educação e com o padrão dependente de desenvolvimento nos governos petistas (2003/2016), ainda que apresentassem, em certo grau, novas roupagens, seguiram operando novidades, continuidades e aprofundamentos desses padrões. Em 2016, o esgotamento da política de coalizão de classes se materializa no impeachment sofrido por Dilma Rousseff, conduzido pelas empreiteiras, pelo agronegócio, pelo capital financeiro, bem como pelo sistema judiciário e midiático, tendo apoio da sociedade civil, sobretudo, classe média/alta. Lima, K. (2017) ressalta que

Estas frações não necessitam mais das negociações conduzidas na fase anterior da contrarrevolução: cooptação de lideranças da classe trabalhadora e seu aburguesamento. Elas evidenciam toda natureza antinacional e antidemocrática da burguesa brasileira, reconduzindo as bases do "capitalismo selvagem” em sua mais pura expressão (LIMA, 2017, p. 101).

Na conjuntura recente, pós 2016, temos um cenário de perversidade, em que a burguesia brasileira expressa com mais profundidade seu caráter violento e antidemocrático, nos governos de Michel Temer (2016-2018) e de Jair Bolsonaro (a partir de 2019). Podemos elencar diversas ações que caracterizam essa face de maior ataque aos direitos historicamente conquistados pelos trabalhadores, como a Emenda Constitucional no 95/2016, que prevê o congelamen- 
to de investimentos públicos em saúde, educação e assistência social por 20 anos; a contrarreforma do Ensino Médio; o Projeto Escola "Sem Partido", a proibição do debate de gênero nas escolas, cortes orçamentários severos nas universidades públicas e institutos federais, censura e perseguição à produção científica crítica e criativa, entre outras ações.

Todavia, conforme aponta Fernandes (1995, p. 114), “[...] a repressão e a opressão nunca tiveram esse poder de paralisar ou congelar a história" e, por isso, há uma intensificação dos desafios e da luta de classes e os secundaristas têm se destacado na organização e na resistência política. As ocupações, em 2016, representaram um grande marco de resistência, pela capilaridade nacional que o movimento político e pedagógico conduziu. Dessa maneira, a pesquisa que realizamos (PAQUIELLA, 2019) revelou que os estudantes que realizaram a ocupação dos IFs partiam das seguintes considerações: Ocupar porque se sentiam pertencentes, identificam-se com a luta coletivamente construída na defesa da educação pública, gratuita, de qualidade, laica, socialmente referenciada, em que a lógica mercadológica, competitiva, meritocrática e individualista não os servem mais. Resistir para existir e ser pulsante na combatividade aos ataques históricos. Florescer uma luta pelo desejo coletivo de uma sociabilidade mais justa, igualitária e livre.

Florestan Fernandes (1989) aponta que a universidade (e aqui, englobamos os espaços escolares e os institutos federais) "[...] precisa cumprir suas funções de uma maneira diferenciada, flexível, sem excluir os oprimidos, os marginalizados e, ao mesmo tempo, envolver uma pedagogia da desopressão. Isto é, ela deve extinguir a consciência colonial, colonizada e oprimida do brasileiro". (FERNANDES, 1989, p. 110).

\section{CONSIDERAÇÕES FINAIS}

Caminhar na construção dessas reflexões aqui apresentadas foi uma oportunidade de recuperar o diálogo com o pensamento sociológico e educacional do saudoso intelectual militante Florestan Fernandes que se destacou, ao longo de sua trajetória, pelo rigor metodológico e o compromisso com a classe trabalhadora, e por isso, construiu seus estudos, a partir da ótica "dos de baixo", conforme ele denominava. Dessa maneira, Florestan Fernandes sempre reforçou a importância de disputar a narrativa, a história e luta da classe trabalhadora no Brasil, que tem a vida atravessada por tantas violências estruturais. 
Ao longo do texto, estabelecemos interlocução com a obra do sociólogo, para apreenderemos sobre o padrão dual de expropriação da classe trabalhadora, o padrão compósito de hegemonia burguesa, a heteronomia cultural, visto que são elementos estruturantes do capitalismo dependente no Brasil e para analisar a configuração, a relação entre educação e território e como se dá a manifestação da dualidade educacional precisamos apreender essas particularidades.

Buscamos, portanto, examinar o modelo de educação que está em pauta no capitalismo dependente; para quem e para que servem os Institutos Federais; e qual é o projeto de educação para a juventude trabalhadora, abordando a política de interiorização e expansão da rede federal e considerando as violações sistemáticas de direitos sociais da juventude pobre, negra e periférica desse país. Assim, compreendendo as problematizações sobre a formação social brasileira, o modelo educacional vigente, a configuração da cidade capitalista e os projetos destinados a juventude trabalhadora buscamos entender como a dualidade educacional, constitutiva no capitalismo dependente, expressa-se com particularidades e novidades no interior dos Institutos Federais, particularmente no IFRJ São Gonçalo.

Finalmente, consideramos que é indispensável abordar os movimentos de resistências protagonizadas pelos secundaristas, com destaque às ocupações, que ocorreram em 2016, no Brasil, resgatando a memória dessa mobilização, que abriu espaço para diversos questionamentos sobre práticas educativas, políticas, de resistência mais horizontais, diversas, criativas e críticas. Assim, encontramos nas frestas que permeiam o movimento, a possibilidade de questionar e colocar em xeque a heteronomia cultural e a dualidade educacional estruturante, buscando a todo instante quebrar e ultrapassar os muros institucionais e burocráticos que isolam e abafam a potência do conhecimento, tensionando o modelo da política educacional e o uso segregado do território em nosso país.

\section{REFERÊNCIAS}

ABREU, M. de A. A evolução urbana no Rio de Janeiro. Rio de Janeiro: IPP, 2008.

BRASIL. Constituição da República Federativa do Brasil de 1988. Brasília. Presidência da República. [1988]. Disponível em: <http://www.planalto.gov.br/ccivil 03/constituicao/constituicao.htm>. Acesso em: 28 set. 2020. 
Decreto $\mathrm{n}^{\circ} \mathbf{2 . 2 0 8}$, de 29 de 17 de abril de 1997. Regulamenta o $\ 2^{\circ}$ do Art.36 e os Arts. 39 a 42 da Lei n. ${ }^{\circ}$ 9.394, de 20 de dezembro de 1996, que estabelece as diretrizes e bases da educação nacional. Brasília. Presidência da República, [1997]. Disponível em: < https://www.planalto.gov.br/ccivil 03/decreto/d2208.htm >. Acesso em: 28 set. 2020.

Decreto $\mathbf{n}^{\circ} \mathbf{5 . 1 5 4}$, de 23 de julho de 2004. Regulamenta o $\int$ o $2^{\circ}$ do Art. 36 e os Arts. 39 a 41 da Lei no 9.394, de 20 de dezembro de 1996, que estabelece as diretrizes e bases da educação nacional, e dá outras providências. Brasília. Presidência da República, [2004]. Disponível em: < http://www.planalto.gov.br/ccivil 03/ato2004-2006/2004/decreto/d5154.htm>. Acesso em: 28 set. 2020 .

Decreto $\mathbf{n}^{\circ} \mathbf{1 1 . 1 9 5}$, de 11 de novembro de 2005. Dá nova redação ao $\int 5^{\circ}$ do art. $3^{\circ}$ da Lei $n^{\circ} 8.948$, de 8 de dezembro de 1994. Brasília. Presidência da República, [2005]. Disponível em: < https://www.planalto.gov.br/ ccivil 03/ ato2004-2006/2005/lei/111195.htm>. Acesso em: 28 set. 2020.

Lei $\mathbf{n}^{\circ} \mathbf{8 . 0 6 9}$, de 13 de julho de 1990. Dispõe sobre o Estatuto da Criança e do Adolescente e dá outras providências. Brasília. Presidência da República, [1990]. Disponível em: < http://www.planalto.gov.br/ccivil 03/leis/ 18069.htm>. Acesso em: 11 set. 2020.

Lei $\mathbf{n}^{\circ}$ 11.249, de 23 de dezembro de 2005. Abre aos Orçamentos Fiscal e da Seguridade Social da União, em favor dos Ministérios da Ciência e Tecnologia, da Educação, da Cultura e do Esporte, crédito suplementar no valor global de $\mathrm{R} \$ 422.037 .761,00$, para reforço de dotações constantes da Lei Orçamentária vigente, e dá outras providências. Brasília. Presidência da República, [2005]. Disponível em: <http://www.planalto.gov.br/ccivil_03/Ato20042006/2005/Lei/L11249.htm>. Acesso em: 28 set. 2020.

. Lei $\mathbf{n}^{\circ}$ 11.892, de 29 de dezembro de 2008. Institui a Rede Federal de Educação Profissional, Científica e Tecnológica, cria os Institutos Federais de Educação, Ciência e Tecnologia. Brasília. Presidência da República, [2008]. Disponível em: < http://www.planalto.gov.br/ccivil 03/ Ato20072010/2008/Lei/L11892.htm>. Acesso em: 28 set. 2020. 
Lei $\mathbf{n}^{\circ}$ 12.711, de 29 de agosto de 2012. Dispõe sobre o ingresso nas Universidades Federais e nas Instituições Federais de Ensino Técnico de Nível Médio. Brasília. Presidência da República, [2012]. Disponível em: $<\underline{\text { http: } / /}$ www.planalto.gov.br/ccivil 03/ ato2011-2014/2012/lei/112711.htm>. Acesso em: 28 set. 2020.

Emenda Constitucional n ${ }^{\circ}$ 95, de 15 de dezembro de 2016. Altera o Ato das disposições constitucionais transitórias, para instituir o novo regime fiscal, e dá outras providências. Brasília. Presidência da República, [2016]. Disponível em: < http://www.planalto.gov.br/ccivil 03/constituicao/emendas/ emc/emc95.htm>. Acesso em: 28 set. 2020.

CARNEIRO. A. S. A construção do outro como não-ser como fundamento do ser. Tese (Doutorado em Educação). Programa de Pós Graduação em Educação. Universidade de São Paulo, São Paulo. p. 339. 2005. Disponível em: $<$ https://negrasoulblog.files.wordpress.com/2016/04/a-construc3a7c3a3o-dooutro-como-nc3a3o-ser-como-fundamento-do-ser-sueli-carneiro-tese1.pdf $>$. Acesso em: 28 set. 2020.

ESTADO DO RIO DE JANEIRO. Lei $\mathbf{N}^{\mathbf{0}} \mathbf{7 . 8 3 0}$ de $\mathbf{0 3}$ de janeiro de $\mathbf{2 0 1 8 .}$ Altera a Lei 4.510, de 13 de janeiro de 2005, reconhecendo o direito a gratuidade nos transportes aos estudantes das redes públicas municipal e federal, como previsto na Lei 3.339, de 29 de dezembro de 1999. Diário Oficial do Estado do Rio de Janeiro. Rio de Janeiro. ano XLIV, nº 003.04 jan. 2018.

FERNANDES, F. Capitalismo Dependente e Classes Sociais na América Latina. 2. ed. Rio de Janeiro. Zahar Editores. 1975a.

. Universidade Brasileira: Reforma ou Revolução? São Paulo: AlfaÔmega. 1975b.

A revolução burguesa no Brasil. Ensaio de Interpretação Sociológica. 2. ed. Rio de Janeiro. Zahar Editores. 1976.

. O desafio educacional. São Paulo: Cortez: 1989. 
. Em busca do socialismo: últimos escritos \& outros textos. São Paulo: Xamã, 1995.

Mudanças sociais no Brasil. Aspectos sobre o desenvolvimento da sociedade brasileira. 1. ed. dig. São Paulo: Global editora, 2013.

FÓRUM LOCAL DA AGENDA 21 DE SÃO GONÇALO. Agenda 21 São Gonçalo. São Gonçalo. 2011. 172p. Disponível em: < http:/ / casafluminense.org.br/wp-content/uploads/2017/08/Agenda-21_SG.pdㅍ> . Acesso em: 11 set. 2020 .

INSTITUTO BRASILEIRO DE GEOGRAFIA E ESTATÍSTICA (IBGE). Censo Brasileiro de 2010. Rio de Janeiro, IBGE, 2012. Disponível em: $<$ https://cidades.ibge.gov.br/brasil/rj/sao-goncalo/pesquisa/23/25207? tipo $=$ ranking $>$. Acesso em: 28 set. 2020.

LEFEBVRE, H. O direito à cidade. Trad. Rubens Eduardo Frias. São Paulo: Centauro, 2001.

LIMA, G. F. Educação Pública e Combate à Pobreza: A Política de Assistência Estudantil no IFRJ/ Campus São Gonçalo (2008/2015). Rio de Janeiro, 2017. 247f. Tese (Doutorado em Serviço Social) - Escola de Serviço Social, Universidade Federal do Rio de Janeiro, Rio de Janeiro, 2017.

LIMA, K. R. de S. Reforma da educação superior nos anos de contra-revolução neoliberal: de Fernando Henrique Cardoso a Luís Inácio Lula da Silva. 2005. 462 f. Tese (Doutorado em Educação) - Faculdade de Educação, Universidade Federal Fluminense, Niterói, 2005.

. Brasil em tempos de contrarrevolução. Revista Universidade e Sociedade, Brasília, n 59, p. 92-103, jan. 2017.

MINTO, L. W. Educação e lutas sociais no Brasil pós-ditadura: da democratização à ausência de alternativas. Revista HISTEDBR On-line, Campinas, SP, v. 13, n. 54, p. 242-262, 2014. DOI: 10.20396/rho.v13i54.8640181. Disponível em: <https://periodicos.sbu.unicamp.br/ojs/index.php/histedbr/ article/view/8640181 >. Acesso em: 28 set. 2020. 
MORAES, C. B. Ressuscita São Gonçalo: a luta por moradia na ocupação Zumbi dos Palmares do Movimento dos Trabalhadores Sem Teto. 2016. 180 f. Dissertação (Mestrado em Serviço Social e Desenvolvimento Regional) - Escola de Serviço Social, Universidade Federal Fluminense, Niterói, 2016.

TEIXEIRA, L. L. Contra-revolução prolongada e reforma da educação profissional: uma análise à luz do pensamento de Florestan Fernandes (19902010). 2012. 303 f. Dissertação (Mestrado em Educação) - Faculdade de Educação, Universidade Federal Fluminense, Niterói, 2012.

VIANA, J. N. L. Rupturas e continuidades: a produção do espaço e o processo de reestruturação: um olhar a partir de são gonçalo. 2019. 312 f. Tese (Doutorado em Geografia Humana) - Faculdade de Filosofia, Letras e Ciências Humanas, Universidade de São Paulo, São Paulo, 2019.

PAQUIELLA, L. de M. Novas faces da dualidade educacional brasileira: territorialidade e os institutos federais. 2019. 159 f. Trabalho de Conclusão de Curso (Serviço Social) - Escola de Serviço Social, Universidade Federal Fluminense, Niterói, 2019. 